\title{
QuAnTification AND Preliminary Estimation OF ToXiC EFFEcts of Polycyclic AROMATIC Hydrocarbon in Some Antimalarial Herbal Drugs in SOUTHWEST Nigeria
}

\author{
Sunday A. Akintelu*, Babawale E. Abiola, Samuel O. Ajayi and Ojeyemi M. Olabemiwo \\ Department of Pure and Applied Chemistry, Faculty of Pure and Applied Sciences, Ladoke Akintola \\ University of Technology, Ogbomoso, Oyo State, Nigeria \\ ${ }^{*} E$-mail: akintelusundayadewale@gmail.com \\ Tel.: +2348036021055 .
}

Received: Feb 20, 2018 / Revised: Mar 15, 2018 / Accepted: Mar 16, 2018

\begin{abstract}
The presence of polycyclic aromatic hydrocarbons (PAHs) in our environment, food and herbal drugs have been linked to many negative health impacts in human. This has elicited a growing interest in scientific investigation into qualitative and quantitative evaluation of PAHs in foods, drugs and environment herbal drugs. The aim of this study was to determine PAHs in some antimalarial herbal drugs sold in southwest Nigeria and to estimate their potential health risks. Five antimalarial herbal drugs found in local market in southwest Nigeria were purchased and used for this study. The PAHs in these herbal drugs samples were extracted using an ultrasonicator and analyzed using Gas Chromatography-Flame Ionization Detector (GC-FID). Daily exposure and cancer risk parameters of the PAHs were estimated. The sum of PAHs in the samples ranged from 26.38 in sample $E$ to 33.54 $\mathrm{mg} / \mathrm{kg}$ in sample $D$ while an average sum of the PAHs in the five samples was $29.25 \mathrm{mg} / \mathrm{kg}$. The percentage of carcinogenic PAHs in these herbal drugs ranged from $7.99 \%$ in sample $D$ to $15.78 \%$ in sample $C$. The source diagnostic indices showed that the source of PAHs in all the five antimalarial herbal drugs were pyrogenic in nature. The cancer risk estimated for children, preteen and adult with body weight $19 \mathrm{~kg}, 48 \mathrm{~kg}$ and $65 \mathrm{~kg}$ using these herbal drugs ranged from $0.64 \times 10^{-7}$ to 3.16

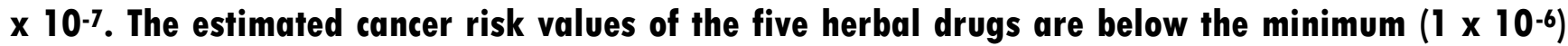
that can cause cancer which is as established by USEPA. This suggests that the use of any of the selected antimalarial herbal drugs may not cause cancer. However, overdose and bioaccumulation cases, calls for the need for analytical information on the profile of PAHs in the herbal drugs.
\end{abstract}

Key words: Polycyclic aromatic hydrocarbons, Malaria, Herbal drugs, GC-FID, Toxic effect.

\section{INTRODUCTION}

Polycyclic aromatic hydrocarbons (PAHs) are a class of organic compounds that result from high-pressure or incomplete combustion processes and are made up of two or more benzene rings that are fused together (Mottier et al 2000). PAHs are also called polycyclic organic matter (POM), polynuclear aromatics (PNAs), polynuclear aromatic hydrocarbons, polynuclear hydrocarbons and are natural fraction of most fossil fuels. Some are from volcanoes and forest fires while most PAHs in ambient air are the result of man-made processes (Zedeck, 1980).

Literature is enriched with reports indicating that herbal drugs are contaminated by PAHs in the course of their preparation especially for herbal drugs which are exposed to direct contact with flame from biomass during their production (Cui et al 2014). In their study, the presence of PAHs in seventy nine Chinese herbal drugs sold 
in China was reported. About $24.1 \%$ of the samples analyzed contained benzo(a)pyrene in quantities which were above maximum permissible limit $(5 \mathrm{mg} / \mathrm{kg}$ ) set by USEPA. Further, eight genotoxic polycyclic aromatic hydrocarbons were detected during analysis of herbal drug products (Krajian and Odeh, 2013) which indicated high contamination with carcinogenic PAHs. There were some study reports which opined that herbal medicines usually contains PAHs and also showed the importance of evaluating the safety of herbal drugs. Their inference was based on the fact that 29 herbal medicines investigated were found to contain carcinogenic PAHs (Kataoka et al 2010).

In the last two decades, the Nigeria pharmaceutical market is been flooded with various brands of modern packaged herbal drugs, most of which are produced locally. Patronage of these herbal drugs, has also witnessed a substantial growth. The increase in production and use of herbal drugs might be due to economic and social factors coupled with the readily availability of these herbal drugs which do not need the prescription of medical personnel before consumption. Presently, in Nigeria, there appears to be no stringent enforcement of law regulating the quality, production, distribution, sale and use of herbal drugs. Herbal drugs have been linked with many toxic effects due to presence of PAHs and some other contaminants in them (Cui et al 2014).Thus, herbal drug has become an integral part of health care system worldwide and are concerned with diverse biological effects due to their vital constituents (Dahiya, 2007; Dahiya and Kumar, 2008; Emran et al 2012; Agarwal et al 2015; Degirmenci et al 2016; Gajendiran et al 2016; Shrestha et al 2016; Dahiya et al 2017; Oloke et al 2017; Dahiya and Singh, 2017; Senthil Kumar et al 2017; Viana et al 2017). Thus, for safety purpose, premium attention must be placed on the standardization of herbal drugs. This informed our desire to carryout surveillance analytical and toxicological assessment of five randomly selected antimalarial herbal drugs in Southwest Nigeria.

\section{MATERIALS AND METHODS}

All reagents used in this study including acetone, $n$-hexane, aluminum oxide, silica gel, diethyl ether and methanol were of analytical grade. Apparatus and equipment used included Ultrasonic bath-Elmsonic S40H, column chromatography, Gas Chromatography-Flame
Ionization Detector (GC-FID).

\section{Sample collection}

Five antimalarial herbal drugs which are locally produced and sold in south west Nigeria namely; 'Jedi' malaria herbal drug (produced in Ibadan Oyo state) coded A, Original malaria herbal drug (produced in Aromole Ogbomoso, Oyo state) coded B, 'Ogun Iba' (by Alhaji Ekiti, Awo Ekiti, Ekiti state) coded C, 'Ogun Iba' (by alhaji Raji Osogbo Osun state) coded D and 'Ogun iba ati inurirun' (by Alhaji Ekiti, Oke Eso Ilesa, Osun state) coded E were purchased. The samples were separately oven dried, grounded and kept in separate air tight glass containers for further analyses.

\section{Extraction of PAHs from selected antimalarial herbal drugs}

Ten grams of each of the air dried herbal drug samples were weighed into different test tubes which had been properly labeled and were ultrasonically extracted with mixture of $n$ hexane and acetone (1:1) for $20 \mathrm{~min}$. The extract for each sample was decanted into different labelled conical flasks. This procedure was repeated on the residue of each of the sample in the test tube with $20 \mathrm{ml}$ of $n$-hexane for two other times and the extracts were decanted into the labelled flasks. The extract of each sample was filtered using ultrapure filter paper that have been pre-treated with $n$-hexane in a sonicator and dried in the oven. The filtrate was collected into a round bottom flask and was concentrated to about $1.5 \mathrm{ml}$ on a rotary evaporator.

\section{Clean-up of extract antimalarial herbal drugs for PAHs analysis}

Contaminants such as lipids and pigments that may have been extracted with PAHs were removed through the clean-up. The clean-up was done using the column chromatography; a column of $1 \mathrm{~cm}$ internal diameter was packed with aluminum oxide and silica gel in ratio 1:3 (first filled with $3 \mathrm{~g}$ of aluminum oxide, then packed with the $9 \mathrm{~g}$ of silica gel). The extract was quantitatively transferred into the prepared column. It was then eluted with $100 \mathrm{ml}$ of acetone and hexane mixture (1:4). An evaporating flask was used for the collection of the eluate to aid proper dryness. The eluate was dissolved with $1 \mathrm{ml}$ of hexane, the resulting solution was injected into Gas ChromatographyFlame Ionization Detector (GC-FID) for analysis. 


\section{Chromatographic conditions}

Column : C-8, $250 \mathrm{~mm} \times 4.6 \mathrm{~mm}, 5 \mu$; Flow rate : $1.2 \mathrm{ml} / \mathrm{min}$; Wavelength : $210 \mathrm{~nm}$; Column temperature : $45^{\circ} \mathrm{C}$; Injection volume : $1 \mu \mathrm{l}$; Run time : $15 \mathrm{~min}$; Diluent : Mobile phase (helium and nitrogen gas); Elution : Isocratic.

\section{Benzo(a)pyrene toxicity equivalent concentration of selected antimalarial herbal drugs}

The benzo(a)pyrene toxicity equivalent concentration was used to determine the cancer potential of the selected antimalarial herbal drugs and was calculated using the model (Orisakwe et al 2015a).

$\mathrm{TEQ}=\Sigma(\mathrm{PAHi} \times \mathrm{TEFi})$

Where PAHi $\rightarrow$ concentration of individual carcinogenic polycyclic aromatic hydrocarbons; TEFi $\rightarrow$ toxic equivalent factor (potency relative to benzo(a)pyrene) and TEQ $\rightarrow$ toxic equivalence.

\section{Cancer risk estimation (Orisakwe et al 2015a)}

Exposure dose $=($ Concentration $\times$ intake rate $\times$ conversion factor $\times$ exposure factor) / Weight of the body

where dose $\rightarrow$ estimated exposure dose; intake rate $\rightarrow$ volume of herbal drugs $6.0 \mathrm{~g}$ per day; weight of the body $\rightarrow$ children $19 \mathrm{~kg}$, preteens 48 $\mathrm{kg}$ and adults $65 \mathrm{~kg}$; conversion factor $\rightarrow 10^{-6}$; exposure factor $\rightarrow 3$ times every 21 days $=$ $52 / 365$; concentration $\rightarrow$ concentration of total toxicity equivalent of benzo(a)pyrene.

Cancer risk estimation $=$ Exposure dose $\times$ Number of year of drinking antimalarial herbal drugs $\times \mathrm{CPF}$ ) / Average life time

where $\mathrm{CPF} \rightarrow$ cancer potency factor and its (7.3) for benzo(a)pyrene; number of years drinking antimalarial herbal drugs $\rightarrow$ assumed to be 30 years; average life time $\rightarrow 55$ years.

\section{RESULTS AND DISCUSSION}

The qualitative and quantitative profile of PAHs detected in the five herbal drugs analyzed are presented in Table 1. Samples A and D contained the sixteen WHO priority PAHs. Acenaphthylene and fluorene were not detected in sample C; pyrene, chrysene, benzo(k)fluoranthene and benzo(a)pyrene were absent in sample D; acenaphthene, fluoranthene and benzo(b)fluoranthene were not detected in sample E. The total sum of PAHs found in the five samples analyzed in this study ranged from $26.37 \mathrm{mg} / \mathrm{kg}$ in sample E to $33.54 \mathrm{mg} / \mathrm{kg}$ in sample D, with an average of $29.25 \mathrm{mg} / \mathrm{kg}$ for all the samples. The total sum of PAHs in each of the samples was above the WHO acceptable limit of $10 \mathrm{mg} / \mathrm{kg}$ for herbal drugs. This may cause an hazardous health implication which was in agreement with results of previously published report (Orizakwe et al 2015a).

Table 1. PAHs profiles in the selected antimalarial herbal drug samples

\begin{tabular}{|c|c|c|c|c|c|c|c|}
\hline \multirow{2}{*}{ Name of PAHs } & \multicolumn{7}{|c|}{ PAHs Concentration (mg/kg) } \\
\cline { 2 - 8 } & A & B & C & D & E & Total & Average \\
\hline Naphthalene & 7.14 & 6.11 & 7.11 & 7.21 & 7.39 & 34.96 & 6.99 \\
\hline Acenaphthylene & 9.23 & 9.21 & 10.00 & 10.21 & 9.60 & 48.25 & 9.65 \\
\hline Acenaphthene & 4.02 & 4.04 & N.D & 4.82 & N.D & 12.88 & 4.29 \\
\hline Fluorene & 0.67 & 0.56 & N.D & 0.80 & 0.66 & 2.69 & 0.67 \\
\hline Phenanthrene & 0.52 & 0.42 & 0.50 & 0.52 & 0.52 & 2.46 & 0.61 \\
\hline Anthracene & 1.38 & 1.27 & 1.50 & 2.84 & 1.39 & 8.39 & 1.68 \\
\hline Fluoranthene & 0.20 & 0.19 & 0.18 & 0.25 & N.D & 0.81 & 0.20 \\
\hline Pyrene & 0.04 & 0.04 & 0.04 & N.D & 0.04 & 0.16 & 0.04 \\
\hline Benzo(a)anthracene & 0.33 & 0.31 & 0.32 & 0.33 & 0.33 & 1.62 & 0.32 \\
\hline Chrysene & 0.25 & 0.28 & 0.24 & N.D & 0.25 & 1.02 & 0.26 \\
\hline Benzo (b) fluoranthene & 0.61 & 0.60 & 0.60 & 0.61 & N.D. & 2.42 & 0.61 \\
\hline Benzo (k) fluoranthene & 0.58 & 0.60 & 0.59 & N.D & 0.52 & 2.29 & 0.57 \\
\hline Benzo (a) pyrene & 0.49 & 0.50 & 0.50 & N.D & 0.50 & 1.99 & 0.50 \\
\hline Indeno(1,2,3-cd)pyrene & 1.29 & 1.20 & 1.20 & 1.30 & 1.29 & 6.27 & 1.25 \\
\hline Dibenzo(a,h)anthracene & 0.79 & 0.80 & 0.74 & 0.44 & 0.79 & 3.55 & 0.71 \\
\hline Benzo(g,h,i)perylene & 3.14 & 3.00 & 3.01 & 4.21 & 3.11 & 16.47 & 3.29 \\
\hline Total PAHs & 30.67 & 29.13 & 26.53 & 33.54 & 26.38 & 146.24 & 29.25 \\
\hline$\Sigma$ Carcinogenic PAHs & 4.34 & 4.30 & 4.19 & 2.68 & 3.67 & 19.18 & 3.84 \\
\hline \% Carcinogenic PAHs & 14.16 & 14.76 & 15.78 & 7.99 & 13.92 & 66.61 & 13.32 \\
\hline
\end{tabular}




\section{Carcinogenic PAHs}

Benzo(a)anthracene, benzo(b)fluoranthene, indeno(1,2,3-c,d)pyrene, benzo(k)fluoranthene, chrysene, benzo(a)pyrene and dibenzo(a,h) anthracene are designated as carcinogenic PAHs, according to WHO. The proportions of the carcinogenic PAHs found in the herbal drugs analyzed in this study ranged from $7.99 \%$ in sample D to $15.78 \%$ in sample C. The occurrence of PAHs in the selected antimalarial herbal drugs might be as a result of incomplete combustion during processing stage and particle bound PAHs on growing leaves of plants from which the herbal drugs were made (Ding and Kaminsky, 2003).

Consequent upon this, the sources of PAHs were investigated using appropriate indexes as discussed below. PAHs in materials can be from pyrogenic or petrogenic sources. Differentiating between the two sources involves the use of diagnostic indices or ratios. The values of the diagnostic ratios in this study and their indications are as showed in Table 2. The Phe/Ant ratio of the PAHs analyzed in this study was less than 10 in all the selected antimalarial herbal drugs which suggests a pyrogenic source. The Ant/(Ant+Phe) ratio is greater than 0.1 in all the antimalarial herbal drugs which suggests a pyrogenic source. The Flt/(Flt+Pyr) ratio is greater than 0.4 in all the antimalarial herbal drugs which indicates a pyrogenic source. The three source diagnostic indices calculated for the five herbal drugs showed that the source of PAHs in all the selected antimalarial herbal drugs were pyrogenic in nature, in agreement with published report (Domingues et al 2010).

Table 2. Diagnostic indices of the source of PAHs in the selected antimalarial herbal drug samples

\begin{tabular}{|c|c|c|c|c|c|c|c|}
\hline \multirow{2}{*}{ PAH ratio } & $\mathbf{A}$ & $\mathbf{B}$ & $\mathbf{C}$ & $\mathbf{D}$ & $\mathbf{E}$ & $\begin{array}{c}\text { Value of } \\
\text { ratio }\end{array}$ & Indication \\
\cline { 2 - 7 } & $\mathbf{A}$ & 0.33 & 0.33 & 0.18 & 0.37 & $\begin{array}{c}<10 \\
>10\end{array}$ & $\begin{array}{c}\text { Pyrogenic } \\
\text { Petrogenic }\end{array}$ \\
\hline Phe/Ant & 0.37 & 0.75 & 0.75 & 0.85 & 0.73 & $\begin{array}{c}<0.1 \\
>0.1\end{array}$ & $\begin{array}{c}\text { Petrogenic } \\
\text { Pyrogenic }\end{array}$ \\
\hline $\begin{array}{c}\text { Ant/(Ant+ } \\
\text { Phe) }\end{array}$ & 0.73 & 0.82 & 0.81 & 0.0 & 0.0 & $\begin{array}{c}<0.4 \\
>0.4\end{array}$ & $\begin{array}{c}\text { Petrogenic } \\
\text { Pyrogenic }\end{array}$ \\
\hline Flt/(Flt+ Pyr) & 0.83 & 0.82 &
\end{tabular}

Flt $\rightarrow$ Fluoranthene, Pyr $\rightarrow$ Pyrene, Ant $\rightarrow$ Anthracene, Phe $\rightarrow$ Phenanthrene

\section{Toxicity of the antimalarial herbal drugs}

The preliminary investigation of the toxicological effects of the five antimalarial herbal drugs analyzed in this study was based on classification of PAHs (based on number of rings) found in the herbal drugs and theoretical estimation of their potential cancer risk based on the sum of PAHs found in them using equation 1. The distribution of PAHs in the selected antimalarial herbal drugs is as shown in Table 3. The distributions of LMW PAHs in all the samples are greater than that of the MMW and HMW PAHs, except in sample $\mathrm{C}$ where the reverse is the case. According to published report (Lijinsky, 1991), PAHs containing four fused rings are weakly carcinogenic while those with five or six-fused rings are very potent carcinogens. This implies that samples A, $B, D$ and $E$ which contained lesser quantity of MMW and HMW PAHs than LMW PAHs may not be carcinogenic. Further step was taken to investigate the potential toxicity of these herbal drugs by estimating their cancer risk (Orisakwe et al 2015a) using quantity of PAHs in them. The estimation was based on equation 2 and the results are presented in Table 4.

Table 3. Group distribution of PAHs in the selected antimalarial herbal drugs

\begin{tabular}{|c|c|c|c|c|c|}
\hline \multirow{2}{*}{ Number of rings } & \multicolumn{5}{|c|}{ Sample (mg/kg) } \\
\cline { 2 - 6 } & A & B & C & D & E \\
\hline TPAHs & 30.67 & 29.13 & 9.42 & 33.54 & 26.38 \\
\hline LMW PAH (2 and 3) & 22.95 & 21.60 & 1.99 & 26.40 & 19.56 \\
\hline MMW PAHs (4 and 5) & 3.79 & 3.72 & 3.67 & 2.49 & 2.92 \\
\hline HMW PAHs (6 and 7) & 3.93 & 3.80 & 3.75 & 4.65 & 3.90 \\
\hline
\end{tabular}

The cancer risk estimation was calculated with the cancer risk estimation formula (Orisakwe et al 2015a) and the standard value set by USEPA that cancer will occur is $1 \times 10^{-6}$. The cancer risk estimated for $19 \mathrm{~kg}$ body weight of a child on exposure to these herbal drugs ranges from 2.20 
Table 4. Cancer risk estimation for the selected antimalarial herbal drugs

\begin{tabular}{|c|c|c|c|c|c|}
\hline \multirow{2}{*}{ Population group } & \multicolumn{5}{|c|}{ Estimated cancer risk for sample } \\
\cline { 2 - 6 } & $\mathbf{A}$ & $\mathbf{B}$ & $\mathbf{C}$ & $\mathbf{D}$ & $\mathbf{E}$ \\
\hline Children & $3.14 \times 10^{-7}$ & $3.16 \times 10^{-7}$ & $3.04 \times 10^{-7}$ & $2.20 \times 10^{-7}$ & $2.99 \times 10^{-7}$ \\
\hline Preteen & $1.25 \times 10^{-7}$ & $1.25 \times 10^{-7}$ & $1.21 \times 10^{-7}$ & $0.87 \times 10^{-7}$ & $1.20 \times 10^{-7}$ \\
\hline Adult & $0.92 \times 10^{-7}$ & $0.92 \times 10^{-7}$ & $0.89 \times 10^{-7}$ & $0.64 \times 10^{-7}$ & $0.88 \times 10^{-7}$ \\
\hline
\end{tabular}

$\times 10^{-7}$ in sample D to $3.16 \times 10^{-7}$ in sample B, that of $48 \mathrm{~kg}$ body weight preteen ranges from $0.87 \times$ $10^{-7}$ in sample D to $1.25 \times 10^{-7}$ in sample B and 65 $\mathrm{kg}$ body weight of an adult ranges from $0.64 \times$ $10^{-7}$ in sample D to $0.92 \times 10^{-7}$ in sample B respectively in the antimalarial herbal drugs. The cancer risk associated with the usage of these herbal drugs was relatively higher in children than preteen and adults. The result of this investigation agreed with result of previously published report (Orisakwe et al 2015a) but below risk level of $10^{-6}$ as established by USEPA (Orisakwe et al 2015b). This suggests that the intake of any of the selected antimalarial herbal drugs may not be carcinogenic except at chronically exposure levels.

\section{CONCLUSION}

The 16 WHO priority PAHs were found in sample A and B. The total concentration of PAHs in each of the five antimalarial herbal drugs samples is above the WHO acceptable limit (10 $\mathrm{mg} / \mathrm{kg}$ ). The source diagnostic indices showed that the source of PAHs in the five antimalarial herbal drugs were pyrogenic in nature. This implies that the PAHs were introduced during

\section{REFERENCES}

Agarwal A, Bora D, Agarwal C, Kumar R, Choudhary V. CNS stimulant and antidepressant activity of seeds of Abelmoschus esculentus in rats. Bull. Pharm. Res. 2015; 5(2):47-50.

Cui Z, Ge N, Cao Y, Zhang J, Liu Y, Zhou L. Investigation and assessment of polycyclic aromatic hydrocarbons contamination in Chinese herbal medicines. Environ. Chem. 2014;33(5):844-9. [DOI: 10.7524/j.issn.0254-610 8.2014.05.018]

Dahiya R. Synthesis of a phenylalanine-rich peptide as potential anthelmintic and cytotoxic agent. Acta Pol. Pharm. 2007;64(6):509-16.

Dahiya R, Kumar A. Synthetic and biological studies on a cyclopolypeptide of plant origin. J. Zhejiang Univ. Sci. B 2008;9(5):391-400. [DOI: 10.1631/jzus.B0720001]

Dahiya R, Singh S. Synthesis, characterization, and biological activity studies on fanlizhicyclopeptide A. Iran. J. Pharm. Res. 2017;16(3):1176-84.

Dahiya R, Singh S, Kaur K, Kaur R. Total synthesis of a natural cyclooligopeptide from fruits of sugar-apples. Bull. Pharm. Res. 2017;7(3):151. [DOI: 10.21276/bpr.201 7.7.3.4]

Degirmenci NS, Akal ZU, Alpsoy L. Cytotoxic and apoptotic effects of caffeic acid and caffeoyl malic acid on brain glioblastoma (U87-MG). Bull. Pharm. Res. 2016;6(1):7-13. the preparation of the herbal drugs. Toxicological indexes estimated for the five drugs showed that the herbal drugs analyzed in this study may not pose health challenges. This suggestion is based on the fact that the cancer risk estimated values calculated for the samples of the herbal drugs were below the risk levels as established by USEPA. However, overdose and bioaccumulation of any of these herbal drugs can pose a very serious health danger judging from relatively high total PAHs and some carcinogenic PAHs found in them.

Thus, the safe application of any of these herbal drugs requires analytical information as provided by this study. In addition, effective evaluation and monitoring of the quality, wholesomeness and toxicological effects of these drugs and other locally produced herbal drugs are very germane and must be given adequate attention by regulatory authority.

\section{ACKNOWLEDGEMENTS}

The authors acknowledge Mr. Akanji SB, Department of Pure and Applied Chemistry, Research Laboratory, LAUTECH, Ogbomoso, Nigeria for his technical assistance in the work.

[DOI: 10.21276/bpr.2016.6.1.2]

Ding X, Kaminsky LS. Human extrahepatic cytochromes P450, function in xenobiotic metabolism and tissueselective chemical toxicity in the respiratory and gastrointestinal tracts. Ann. Rev. Pharmacol. Toxicol. 2003;43:149-73. [DOI: 10.1146/annurev.pharmtox.43.10 0901.140251]

Dominguez C, Sarkar SK, Bhattacharya A, Chatterjee M, Bhattacharya BD, Jover E, Albaiges J, Bayona JM, Alam MA, Satpathy KK. Quantification and source identification of polycyclic aromatic hydrocarbons in core sediments from Sundarban mangrove wetland, India. Arch. Environ. Contam. Toxicol. 2010;59(1):49-61. [DOI: 10.1007/s0024 4-009-9444-2]

Emran TB, Rahman MA, Zahid Hosen SM, Saha D, Chowdhury S, Saha D, Dey TK. Antioxidant property of ethanolic extract of Leucas aspera Linn. Bull. Pharm. Res. 2012;2(1):46-9.

Gajendiran A, Thangaraman V, Thangamani S, Ravi D, Abraham J. Antimicrobial, antioxidant and anticancer screening of Ocimum basilicum seeds. Bull. Pharm. Res. 2016;6(3):114-9. [DOI: 10.21276/bpr.2016.6.3.5]

Kataoka H, Ishizaki A, Saito K. On-line automated analysis of polycyclic aromatic hydrocarbons - applications to herbal medicines. Chim. Oggi. 2010;28(5):21-4. 
Krajian H, Odeh A. Polycyclic aromatic hydrocarbons in medicinal plants from Syria. Toxicol. Environ. Chem. 2013;95(6):942-53. [DOI: 10.1080/02772248.2013.8403 75]

Lijinsky W. The formation and occurrence of polynuclear aromatic hydrocarbons associated with food. Mutat. Res. 1991;259(3-4);251-61. [DOI: 10.1016/0165-1218(91)90 121-2]

Mottier P, Parisod V, Turesky RJ. Quantitative determination of polycyclic aromatic hydrocarbons in barbecued meat sausages by gas chromatography coupled to mass spectrometry. J. Agric. Food Chem. 2000;48(4): 1160-6. [DOI: 10.1021/jf991205y]

Oloke J, Odelade K, Oladeji O. Characterization and antimicrobial analysis of flavonoids in Vernonia amygdalina: a common chewing stick in south-western Nigeria. Bull. Pharm. Res. 2017;7(3):149. [DOI: 10.21276/ bpr.2017.7.3.2]

Orisakwe OE, Mbagwu HOC, Ukpai P, Udowelle NA. Survey of polycyclic aromatic hydrocarbons and lead in Chinese teas sold in Nigeria: levels and health implications. Rocz.
Panstw. Zakl. Hig. 2015a;66(3):225-32.

Orisakwe OE, Igweze ZN, Okolo KO, Udowellea NA. Human health hazards of poly aromatic hydrocarbons in Nigerian smokeless tobacco. Toxicol. Rep. 2015b;2:1019-23. [DOI: 10.1016/j.toxrep.2015.07.011]

Senthil Kumar R, Vinoth Kumar S, Sudhakar P. Anticancer activity of methanolic leaf extract of Morinda tinctoria roxb. against ehrlich ascites carcinoma in mice. Bull. Pharm. Res. 2017;7(2):146. [DOI: 10.21276/bpr.201 7.7.2.4]

Shrestha DK, Sapkota H, Baidya P, Basnet S. Antioxidant and antibacterial activities of Allium sativum and Allium cepa. Bull. Pharm. Res. 2016;6(2):50-5. [DOI: 10.21276/bpr.201 6.6.2.3]

Viana CB, Carbonezi LH, Martins RCC. Isolation of pentacyclic triterpenes from Simira sampaioana (standl.) steyerm (Rubiaceae) as possible anticancer agents. Bull. Pharm. Res. 2017;7(1):142. [DOI: 10.21276/bpr.201 7.7.1.5]

Zedeck MS. Polycyclic aromatic hydrocarbons: a review. J. Environ. Pathol. Toxicol. 1980;3(5-6):537-67. 